\title{
A Gage Study Applied in Shear Test to Identify Variation Causes from a Resistance Spot Welding Measurement System
}

\author{
Fabrício Alves de Almeida ${ }^{1, *}$ - Guilherme Ferreira Gomes ${ }^{2}$ - Rachel Campos Sabioni ${ }^{3}$ - \\ José Henrique de Freitas Gomes ${ }^{1}$ - Vinícius Renó de Paula ${ }^{1}$ - Anderson Paulo de Paiva ${ }^{1}$ \\ Sebastião Carlos da Costa ${ }^{1}$ \\ ${ }^{1}$ Federal University of Itajubá - Institute of Industrial Engineering and Management, Brazil \\ ${ }^{2}$ Federal University of Itajubá - Mechanical Engineering Institute, Brazil \\ ${ }^{3}$ Sorbonne Universités, Université de Technologie de Compiègne - Department of Mechanical Engineering, France
}

Resistance welding processes, especially spot welding, have wide applicability in the industry, especially in the automotive sector, due to its fast execution and the non-use of consumables. In addition, the search for quality improvement of the final product is incessant and, in a capable process, there should be no error related to the measurements. In this study, the NGR\&R was used by the ANOVA method to identify the variation components of the measurement system in the shear test for two quality characteristics: tensile-shear strength and ultimate strain. The experiments were conducted on a hot dip galvanized steel by using design of experiments to select the parts in order to represent the real amplitude of the process. From the results it was possible to verify that one of the destructive test machines used in this study has a strong variability, evidencing that some adjustments and improvements are necessary in the coupling of the specimens for steels with coating layers (such as galvanized steel, which has a layer of zinc).

Keywords: spot welding, measurement system analysis, shear test, NGR\&R, ANOVA

Highlights

- A nested GR\&R study applied in shear test for a resistance spot welding process.

- Design of experiments to select the parts in order to represent the real amplitude of the process.

- The analysis of variance method to identify variation causes for two tensile machines and two quality characteristics: tensileshear strength and ultimate strain.

- The results showed that Machine 1 presents greater contribution on the system variability, with measurement results outside the control, as well as a lower degree of repetitiveness than Machine 2.

\section{INTRODUCTION}

Resistance spot welding (RSW) is a structural joint technique widely used in the automotive sector [1]. RSW is highlighted among welding processes due to its features that favor the industry such as agile operation, which is easily suitable for automatic processes, simple handling, diverse applications and low cost [2] to [4]. Because of its wide applicability and importance, new methodologies for parameter adjustment have been applied to RSW improvement, contributing to the process control and capability.

Among the available methods for verification of the weld point, there is the shear test, which is characterized by the application of opposing forces causing stress in a sliding movement for a given sample. Since this type of test allows to evaluate the quality of welded point, it is being increasingly used, as described by Feng et al. [5], Zhang et al. [6], Martín et al. [7], Shan et al. [8], Chen et al. [9], Manladan et al. [10].

The search for quality improvements has been leading industries to improve their efficiency.
However, devoting improvements only to the process may not contribute to make it better, as the variability can also be caused by the measurement system. Therefore, it is necessary to verify the measurement system variability in industrial processes, such as RSW.

There are several methods for controlling and monitoring quality in the RSW process, such as: expulsion detection in materials [1] and [11]; strength estimation based on sonic emission [12]; welding current analysis on weld strength [13]; temperature measurement [14]; electrode displacement [15] and [16]; and other types of control (i.e. electrical variables, ultrasound transmission and acoustic emission) [17]. However, the control approaches must be verified through specific tests, which illustrate the mechanical characteristics necessary for their capability evaluation, such as the shear test.

The shear test is characterized as a destructive test that evaluates the mechanical strength of the weld point in relation to shear stresses. Destructive tests are performed from time to time, by sampling, being widely employed in the automotive sector. 
Thereunto, quantitative methods are used to verify the process quality, in which the measuring device must be validated before data collection [18].

The variability in destructive test results may arise from the measurement system itself as well as from the manufacturing process [19] to [21]. In this case, the measurement error must be avoided in experimental procedures.

On the other hand, in quality methodologies such as Six Sigma, before analyzing the process, it is necessary to verify the capability of the measurement system (MS). One of the techniques used to evaluate the variation components of MS, according to Peruchi et al. [22], is gage repeatability and reproducibility (GR\&R), in which the MS variability is quantified and analyzed through an analysis of variance (ANOVA). The repeatability (Fig. 1a) is characterized by the variation within the system under fixed and already defined conditions of measurements (part, environment, operator, instrument among others), i.e., the variation acquired in a measuring equipment used several times by an operator, which is based on a single part [23] to [27].

In this way, the reproducibility (Fig. 1b) is characterized by the average variation between evaluated systems, being the variation found in the mean of different operators using the same equipment to perform the measurement of a single part [23] and [28] to [31].

ANOVA is a statistical method applied together with GR\&R, as described by: Shi et al. [32]; Deshpande et al. [33]; Zhua et al. [34]; García \& del Río [35]; Woodall \& Borror [20]; Johnson et al. [36]. However, there are few applications focused on the RSW process, reinforcing the potential contribution of this work.

There are several studies in scientific literature related to the measurement system analysis on RSW processes, such as: Wan et al. [37]; Degidi et al. [38]; Wang et al. [39]; Xia et al. [40]; Simončič, \& Podržaj [15]; Al-Jader et al. [41]; Lei et al. [42]; Lai et al. [43]; Podržaj et al. [11].

Conduct the measurement system analysis by comparing tensile machines for destructive tests (such as the shear test) on RSW process is original, since published studies that have performed this type of analysis in this process do not present a similar evaluation. In addition, considering the accessed references in this current work, it is possible to confirm the relevance of applying the galvanized steel in this process. Given the importance that a measurement system presents in industrial processes (especially in RSW), this paper aims to perform a gage repeatability and reproducibility for nested design (NGR\&R) applied to the shear test to verify variation causes in a RSW process measurement system, using univariate method ANOVA, comparing two tensile testing machines. The limits of the process parameters were defined from preliminary tests, in order to guarantee desired failure modes. Design of experiments (DOE) methodology was used, being a statistical strategy to model experiments [44], thus that the characteristics of the parts represented a real amplitude of the RSW process.
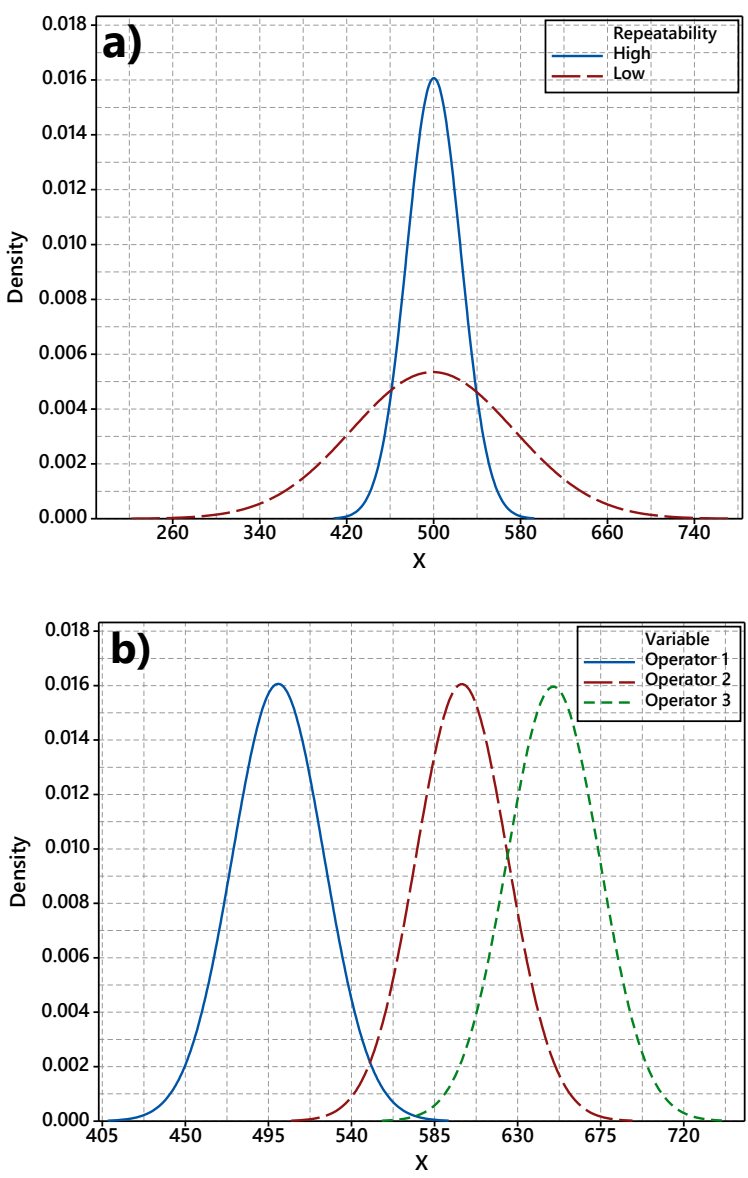

Fig. 1. a) Repeatability and b) reproducibility on a measurement system

This article is organized as follows: a bibliographic review on the RSW process and GR\&R study. Subsequently, section 3 describes the materials and methods used in the development of this work. Experimental and statistical results are presented in section 4. Finally, section 5 presents pertinent and relevant conclusions about the subject. 


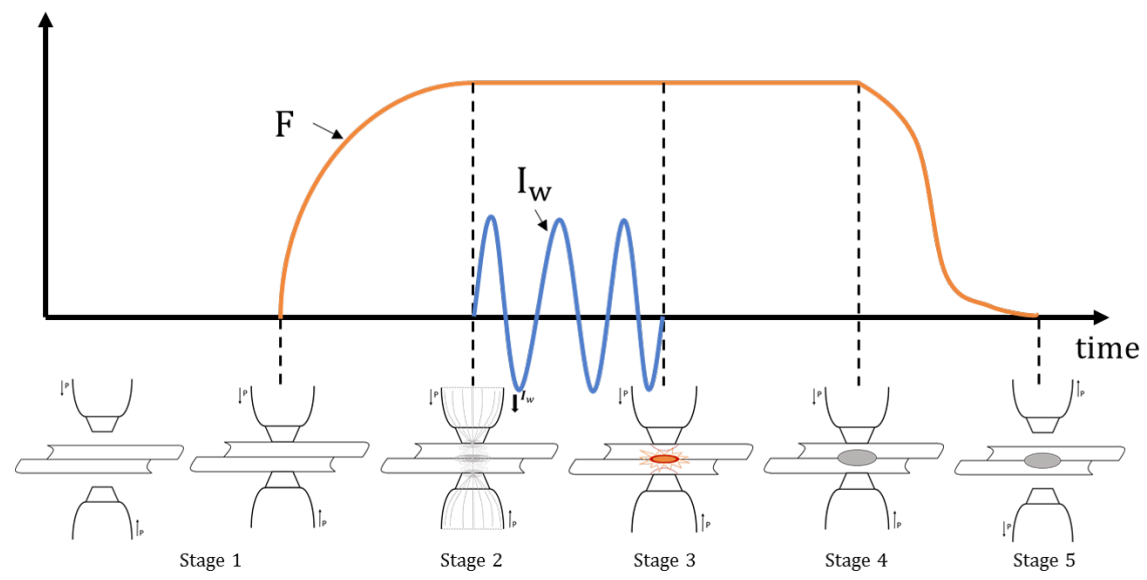

Fig. 2. The spot welding cycle showing the five main phases of the process

\section{THEORETICAL BACKGROUND}

\subsection{The Process of RSW}

Commonly used in large-scale manufacture, the RSW process consists in joining two metal parts through the fusion of the metal, overlaid by two electrodes that generate sufficient force and heat at the weld point, during the passage of an electric current [45].

The welding cycle for RSW presents a series of stages, which are described below:

- Stage 1: the electrodes intercept the parts to be welded, providing a certain force $(\mathrm{F})$ on them and ensuring a good settlement;

- $\quad$ Stage 2: still under pressure, the electric current (Iw) passes through the system initiating the weld point formation;

- Stage 3: after the point being established, the electric current is interrupted, but the mechanical pressure generated by the electrodes is maintained on the pieces until the point solidification;

- $\quad$ Stage 4: the exerted force (F) ceases;

- Stage 5: the electrodes stop intercepting the parts. The sequence of the welding process is presented in Fig. 2.

RSW is controlled by three parameters: welding current, welding time and electrode pressure. These control parameters are presented in several scientific researches which use RSW, such as: Wan et al. [46], Zhang et al. [47], Pouranvari [48], Ighodaro et al. [49], Fan et al. [50], Moos \& Vezzetti [51], Amaral et al. [52], Florea et al. [53], Podržaj \& Simončič [54], Podržaj et al. [55]. Knowing controllable and uncontrollable process factors, as well as adequately configuring these parameters, helps to ensure a good welded product, since these factors impact on its geometry and final quality [56].

There are several types of tests to evaluate the quality and performance of RSW [57], such as destructive tests, which are usually performed by sampling. Such methods are described by the American Welding Society (AWS) [58], in order to guarantee and monitor the quality of welding nugget, as shown in Fig. 3.

It should be noted that in the shear test, the specimens are fixed in specific equipment for tensile tests, in which opposing forces are applied until their rupture, according to the scheme shown in Fig. 3. In this test it is possible to collect the responses of tensile-shear strength (SS) and ultimate strain (US), which may indicate the energy absorbed (toughness) by the specimen.
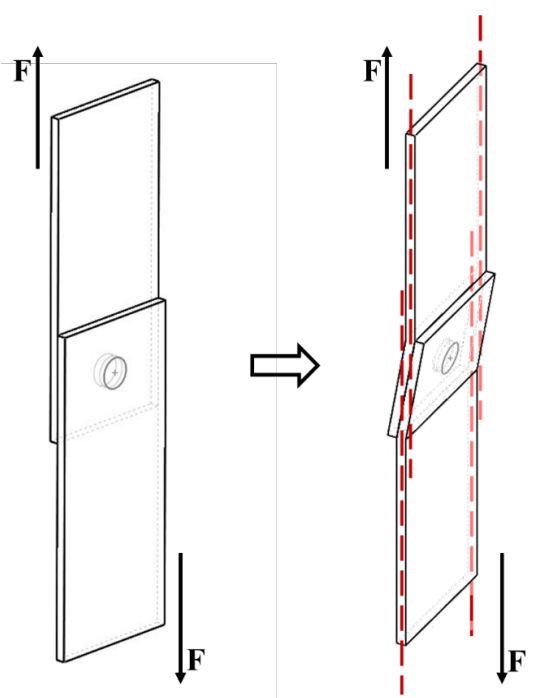

Fig. 3. Shear test on standard specimens after welding 


\subsection{GR\&R Study}

The total process variation comprises the sum of variations derived from measurement system and partto-part. The GR\&R seeks to estimate how much of the total process variation is caused by the measurement system, and determining how significant it is, compared to the part-to-part variation [59].

Two cases of control can be considered for MS, product and process:

- Product: associated with binary decisions, for approved and unapproved products, under 100 $\%$ sample inspections or inspections, in which GR\&R aims to estimate the tolerance of the product, without verifying the process;

- Process: associated to decisions directed to the adequacy of the measurement system to the process control. Searching to stabilize (and understand) the natural process variability in order to make this appropriate.

The process can be divided into a certain number of categories and may be represented from a variability statistics of the MS named number of distinct categories $(n d c)$ [60] and [61]. This paper presents a literature review about this subject. The number of distinct categories must be greater or equal to 5. Table 1 presents the guidelines for the MS acceptance [23].

When a single characteristic is evaluated in GR\&R studies, a single response variable is analyzed in order to verify the measurement system capability. Besides the traditional univariate approaches, Wang \& Chien [31] say that ANOVA, among the known statistical methods, is the best one. ANOVA method stands out in relation to the mean and amplitude (M\&A), because it estimates the variance more accurately. In addition, the ANOVA method presents more information about the data than the M\&A approach.

Table 1. Classification criteria for the measurement system

\begin{tabular}{lc}
\hline Measurement System & GR\&R [\%] \\
\hline Acceptable & $<10$ \\
\hline Marginal & 10 to 30 \\
\hline Unacceptable & $>30$ \\
\hline
\end{tabular}

\subsubsection{Analysis of Variance (ANOVA)}

The variability in measurements of univariate cases can be originated from operator mistakes, measuring instrument variation or even from the product itself. Thus, for a complete GR\&R study, it is mandatory to follow the model described in Eq. (1) [24] and [26].

$$
Y=\mu+\alpha_{i}+\beta_{j}+(\alpha \beta)_{i j}+\varepsilon_{i j k}\left\{\begin{array}{l}
i=1,2, \ldots, p \\
j=1,2, \ldots, o \\
k=1,2, \ldots, r
\end{array} .\right.
$$

In the Eq. (1), $Y$ refers to the response variable, $\mu$ to the values mean, $\alpha_{i} \sim N\left(0, \sigma_{\alpha}\right)$ is the random variable for each part, $\beta_{j} \sim N\left(0, \sigma_{\beta}\right)$ is the random variable for operator, $\alpha \beta_{i j} \sim N\left(0, \sigma_{\alpha \beta}\right)$ refers to the interaction and $\varepsilon_{i j k} \sim N\left(0, \sigma_{\varepsilon}\right)$ is the estimated error term.

When operators cannot measure all parts, which is a common feature in destructive tests, a NGR\&R must be used [62]. This type of design does not present an interaction term between the factors. The variance components for the model are described in Eq. (2).

$$
Y=\mu_{N}+\beta_{j}+\alpha(\beta)_{i(j)}+\varepsilon_{i j k}\left\{\begin{array}{l}
i=1,2, \ldots, p \\
j=1,2, \ldots, o \\
k=1,2, \ldots, r
\end{array},\right.
$$

where $\mu_{N}$ is the average values from the nested design, $\beta_{j} \sim N\left(0, \sigma_{\beta}\right)$ and $\alpha(\beta)_{i(j)} \sim N\left(0, \sigma_{\alpha(\beta)}\right)$ are the random and independent variables for operator and for parts nested within operators, respectively. The $\varepsilon_{i j k} \sim N\left(0, \sigma_{\varepsilon}\right)$ is the estimated error term. Still in the Eq. (2), $p$ is the number of parts, $o$ the number of operators and $r$ the number of replicas.

The variation components of a NGR\&R study with no significant interaction are estimated as in Table 2.

Table 2. Variance components for nested design

\begin{tabular}{lll}
\hline$\sigma_{\text {process }}^{2}$ & $\sigma_{\alpha(\beta)}^{2}$ & $\sigma_{\alpha(\beta)}^{2}=\frac{M S_{\alpha(\beta)}-M S_{\varepsilon}}{r}$ \\
\hline$\sigma_{\text {repeatability }}^{2}$ & $\sigma_{\varepsilon}^{2}$ & $\sigma_{\varepsilon}^{2}=M S_{\varepsilon}$ \\
\hline$\sigma_{\text {reproducibility }}^{2}$ & $\sigma_{\beta}^{2}$ & $\sigma_{\beta}^{2} \frac{M S_{\beta}-M S_{\alpha(\beta)}}{p r}$ \\
\hline$\sigma_{\text {NGR\&R }}^{2}=\sigma_{\text {repeatability }}^{2}+\sigma_{\text {reproducibility }}^{2}$ \\
\hline$\sigma_{\text {total }}^{2}=\sigma_{\text {process }}^{2}+\sigma_{\text {NGR\&R }}^{2}$ \\
\hline
\end{tabular}

Table 2 describes the mean squares for operators, parts within operators and the error term.

In a nested design, the $\% R \& R$ and $n d c$ are the two main indicators commonly used to measure and evaluate the MS [60]:

- $\quad \% R \& R$ is the percentage statistics of repeatability \& reproducibility $(\mathrm{R} \& \mathrm{R})$, which measures the MS standard deviation against the total standard deviation, represented by Eq. (3). 
- $n d c$, also known as the signal-noise index (SNR), measures the variability of the MS. Eq. (4).

$$
\begin{aligned}
& \% N G R \& R=\left(\frac{\sigma_{N G R \& R}}{\sigma_{\text {total }}}\right) \cdot 100[\%], \\
& N-n d c=\left(\frac{2 \sigma_{\text {process }}^{2}}{\sigma_{N G R \& R}^{2}}\right)=1.41 \frac{\sigma_{\text {process }}}{\sigma_{\text {NGR\&R }}} .
\end{aligned}
$$

\section{EXPERIMENTAL PROCEDURE AND PARAMETERS DEFINITION}

All test specimens used in this study were performed on a stationary classification machine (Presol Transweld ${ }^{\circledR}$ brand, model TWPRV50) with rated power of $50 \mathrm{kVA}, \mathrm{AC}$ and maximum current of $6 \mathrm{kA}$, as shown in Fig. 4. In addition, a chromium-zirconium electrode (Group A, class 2) was used for welding the specimens $(0.10 \%$ to $0.15 \% \mathrm{C}, 0.3 \%$ to $0.6 \% \mathrm{Mn}$, $0.005 \% \mathrm{Al}, \leq 0.03 \% \mathrm{P}, \leq 0.05 \% \mathrm{~S}, 40 \mathrm{~g} / \mathrm{m}^{2}$ to 50 $\mathrm{g} / \mathrm{m}^{2} \mathrm{Zn}$ ) with $0.8 \mathrm{~mm}$ thickness. The dimensional specifications of Specimens were made according to the AWS [58] standard, as shown in Fig. 5.

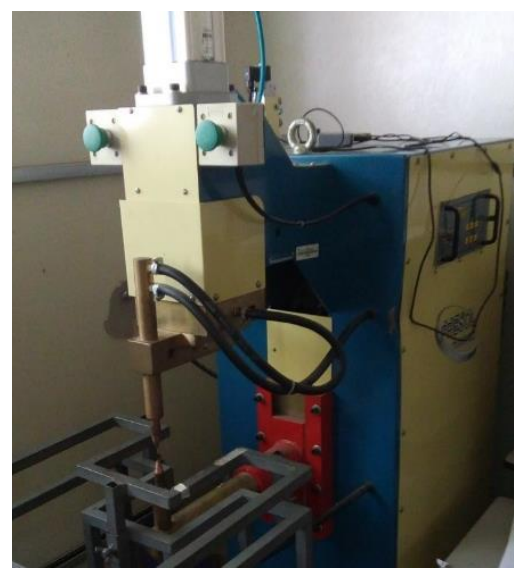

Fig. 4. TWPRV50 Presol Transweld ${ }^{\circledR}$ machine

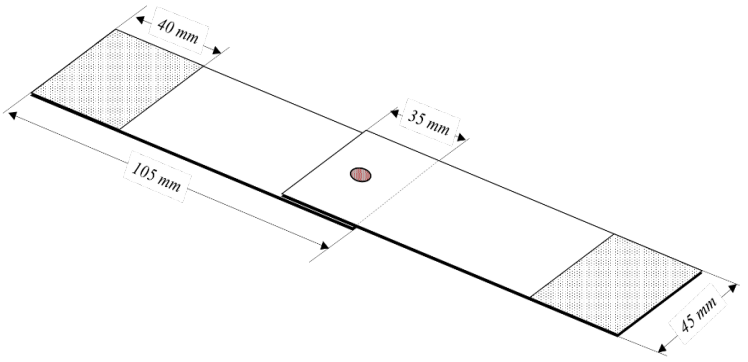

Fig. 5. Dimensions of the specimen for the shear test

The main welding parameters were established based on preliminary tests, thus the minimum parameter limits ensure that the "interfacial" type of failure mode does not occur at the weld point. Table 3 shows the defined values (maximum and minimum). The electrode pressure was set at 2 bar.

Table 3. Control factors and respective levels

\begin{tabular}{lccc}
\hline \multirow{2}{*}{ Setup } & \multirow{2}{*}{ Unit } & \multicolumn{2}{c}{ Levels } \\
\cline { 3 - 4 } & & -1 & +1 \\
\hline$T_{\text {preheating }}$ & Cycles & 5 & 11 \\
\hline$I_{\text {preheating }}$ & $\% \mathrm{kA}$ & 66 & 74 \\
\hline$T_{\text {welding }}$ & Cycles & 7 & 17 \\
\hline$I_{\text {welding }}$ & $\% \mathrm{kA}$ & 75 & 83 \\
\hline
\end{tabular}

From the limits specified in Table 3, the DOE statistical technique was used to generate the fractional factorial design (FFD) as shown in Table 4, in order to have parts with different characteristics as well as representing the process amplitude.

Table 4. Experimental matrix

\begin{tabular}{ccccc}
\hline \multirow{2}{*}{ Run } & \multicolumn{5}{c}{ Setup } \\
\cline { 2 - 5 } & $\begin{array}{c}T_{\text {preheating }} \\
{[\text { cycles] }}\end{array}$ & $\begin{array}{c}I_{\text {preheating }} \\
{[\% \mathrm{kA}]}\end{array}$ & $\begin{array}{c}T_{\text {welding }} \\
{[\text { cycles] }}\end{array}$ & $\begin{array}{c}I_{\text {welding }} \\
{[\% \mathrm{kA}]}\end{array}$ \\
\hline 1 & 11 & 74 & 7 & 83 \\
\hline 2 & 11 & 66 & 17 & 83 \\
\hline 3 & 5 & 74 & 7 & 83 \\
\hline 4 & 11 & 74 & 7 & 75 \\
\hline 5 & 5 & 66 & 17 & 83 \\
\hline 6 & 11 & 66 & 17 & 75 \\
\hline 7 & 5 & 74 & 17 & 83 \\
\hline 8 & 11 & 74 & 17 & 83 \\
\hline
\end{tabular}
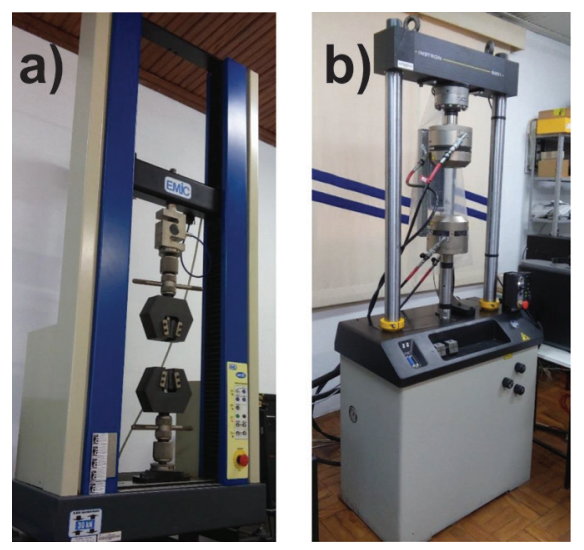

Fig. 6. Equipment used in the shear test: a) $E M I C^{\circledR}$ (Machine 1) and b) Instron ${ }^{\circledR}$ (Machine 2)

Forty-eight welds were performed for shear test. Two operators (or simply the tensile machines) were considered in the NGR\&R study: An EMIC ${ }^{\circledR}$ DL2000 (Fig. 6a) with an axial force of $30 \mathrm{kN}$ and an Instron ${ }^{\circledR}$ hydraulic servomotor model 8801 (Fig. 
6b) with an axial force of $100 \mathrm{kN}$. Table 5 shows the 48 measurements with two critical-to-quality characteristics (CTQ).

\section{RESULTS AND DISCUSSION}

From the data collected in the shear test, two quality characteristics will be analyzed separately, which are tensile-shear strength (TSS) and ultimate strain (US).

Table 5. Measurement of quality responses (CTQ)

\begin{tabular}{|c|c|c|c|c|c|}
\hline \multirow{2}{*}{$i$} & \multirow{2}{*}{$k$} & \multicolumn{2}{|c|}{ Machine 1} & \multicolumn{2}{|c|}{ Machine 2} \\
\hline & & TSS [N] & US [mm] & TSS [N] & US [mm] \\
\hline 1 & 1 & 3217.58 & 1.47 & 3737.14 & 0.3 \\
\hline 1 & 2 & 2783.24 & 0.28 & 3139.77 & 0.22 \\
\hline 1 & 3 & 3247.12 & 0.35 & 3105.44 & 0.2 \\
\hline 2 & 1 & 4779.46 & 1.45 & 5030.16 & 1.14 \\
\hline 2 & 2 & 5498.73 & 2.67 & 5458.82 & 1.21 \\
\hline 2 & 3 & 5326.73 & 1.29 & 5450.11 & 1.31 \\
\hline 3 & 1 & 2096.99 & 0.17 & 2100.57 & 0.09 \\
\hline 3 & 2 & 1747.78 & 0.14 & 2098.47 & 0.09 \\
\hline 3 & 3 & 1848.55 & 0.15 & 2720.33 & 0.14 \\
\hline 4 & 1 & 1228.31 & 0.09 & 2539.37 & 0.11 \\
\hline 4 & 2 & 2199.49 & 0.22 & 2379.70 & 0.11 \\
\hline 4 & 3 & 1388.15 & 0.15 & 2864.78 & 0.14 \\
\hline 5 & 1 & 4484.11 & 1.16 & 5580.03 & 1.35 \\
\hline 5 & 2 & 4395.51 & 1.60 & 4275.08 & 0.81 \\
\hline 5 & 3 & 4482.38 & 1.15 & 4364.20 & 0.91 \\
\hline 6 & 1 & 2413.19 & 0.22 & 4329.65 & 0.9 \\
\hline 6 & 2 & 2593.87 & 0.27 & 3067.30 & 0.15 \\
\hline 6 & 3 & 2011.86 & 0.14 & 2813.81 & 0.13 \\
\hline 7 & 1 & 5385.80 & 1.97 & 4983.90 & 1.16 \\
\hline 7 & 2 & 5378.85 & 6.63 & 4931.34 & 1.13 \\
\hline 7 & 3 & 4935.82 & 1.31 & 5145.93 & 1.15 \\
\hline 8 & 1 & 4656.11 & 1.20 & 5838.03 & 1.37 \\
\hline 8 & 2 & 4607.46 & 1.22 & 4692.68 & 0.95 \\
\hline 8 & 3 & 4711.71 & 1.20 & 4453.84 & 0.82 \\
\hline
\end{tabular}

\subsection{Results for Tensile-shear Strength}

In destructive tests, the TSS vector, which holds the set of original responses of the shear test, does not present an interaction term, so it can be represented by Eq. (2). The analysis of variance for the TSS characteristic is found in Table 6. From the ANOVA, the hypothesis of parts being equal must be rejected, but it is not possible to reject the null hypothesis of different operators replicate the same measurement to a specific part, since $p$-values are equal to 0.561 and 0.000 , respectively.

From Eqs. (3) and (4), it is possible to measure the square roots of variances, the $\% R \& R$ and $n d c$ indicators for the TSS response. Considering the results from Table 7, $\% R \& R$ presented a value of $29.91 \%$, being considered marginal, given the conditions established in Table 1. The number of distinct categories $(n d c)$ identified by the system was classified as unacceptable, according to the AIAG [23] recommendations.

Table 6. ANOVA for TSS results

\begin{tabular}{lccccc}
\hline Source & DF & SS & MS & F & P \\
\hline Operators & 1 & 1952795 & 1952795 & 0.354 & 0.561 \\
\hline Part (Operators) & 14 & 77233406 & 5516672 & 31.5346 & 0.000 \\
\hline Repeatability & 32 & 5598088 & 174940 & - & - \\
\hline Total & 47 & 84784289 & - & - & - \\
\hline
\end{tabular}

Table 7. Variance components contribution of TSS

\begin{tabular}{lcc}
\hline Source & $\sigma$ & \% Contribution \\
\hline$\sigma_{G R \& R}$ & 418.26 & 29.91 \\
\hline$\sigma_{\text {repeatability }}$ & 418.26 & 29.91 \\
\hline$\sigma_{\text {reproducibility }}$ & 0.00 & 0.00 \\
\hline$\sigma_{\text {part-to-part }}$ & 1334.38 & 95.42 \\
\hline$\sigma_{T}$ & 1398.40 & 100 \\
\hline$n d c$ & & 4 \\
\hline
\end{tabular}

In addition, Fig. 7 shows the result of measurements for the TSS characteristic. It is possible to verify the dispersion between the measured values and the average of these values. For this characteristic, it is possible to verify that the two machines (operators) present different values of average for each part, properly representing the process amplitude.

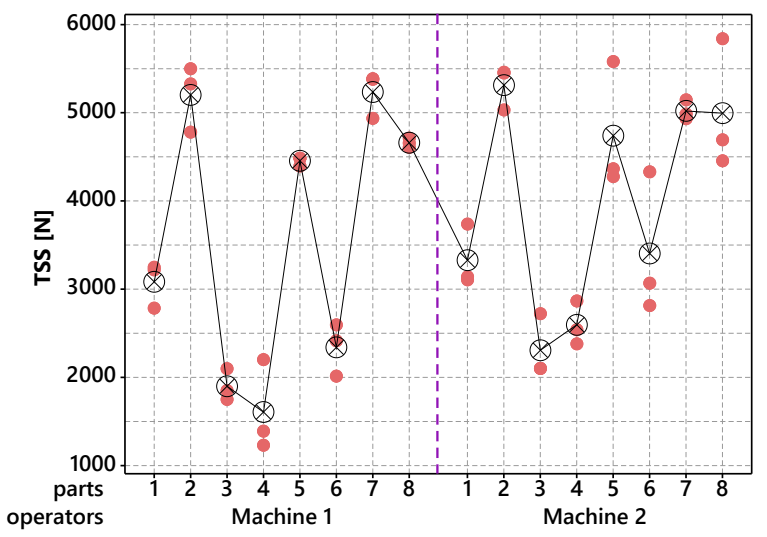

Fig. 7. Measurement results for the TSS characteristic

\subsection{Result for Ultimate Strain}

The same procedure performed for the TSS characteristic was repeated to verify the study for 
the US quality characteristic. From the analysis of variance for the US characteristic (Table 8) it is possible to verify that it does not reject the null hypothesis of operators replicating an equal measurement for the same part ( $p$-value equal to 0.309). However, the null hypothesis of parts being equal must be rejected, confirming that the choice of parts represents the process amplitude.

Table 8. ANOVA for US results

\begin{tabular}{lccccc}
\hline Source & DF & SS & MS & F & P \\
\hline Operators & 1 & 2.3464 & 2.34638 & 1.11418 & 0.309 \\
\hline Part (Operators) & 14 & 29.4829 & 2.10592 & 3.41443 & 0.002 \\
\hline Repeatability & 32 & 19.7367 & 0.61677 & - & - \\
\hline Total & 47 & 51.566 & - & - & - \\
\hline
\end{tabular}

Table 9 presents the results concerning the variation components for the US characteristic calculated from Eqs. (3) and (4). Based on the outcomes, it is possible to verify that the $\% R \& R$ indicator presented a value of $74.4 \%$, being deemed as unacceptable under the established conditions from Table 1. In addition, the number of distinct categories (ndc) identified by the system presented a value equal to 1 , which is considerably unacceptable according to the AIAG [23] recommendations.

Table 9. Variance components contribution of US

\begin{tabular}{|c|c|c|}
\hline Source & $\sigma$ & $\%$ Contribution \\
\hline$\sigma_{G R \& R}$ & 0.7917 & 74.70 \\
\hline$\sigma_{\text {repeatability }}$ & 0.7854 & 74.1 \\
\hline$\sigma_{\text {reproducibilitv }}$ & 0.1001 & 9.44 \\
\hline$\sigma_{\text {part-to-part }}$ & 0.7046 & 66.48 \\
\hline$\sigma_{T}$ & 1.0598 & 00 \\
\hline$n d c$ & & \\
\hline
\end{tabular}

After the results were obtained, the control R chart (Fig. 8a) and boxplot (Fig. 8b) were plotted in order to represent the performance of the two operators to measure the US characteristic. The control R chart highlights the out-of-control point on the Machine 1 for the part 7, which indicates that there was not a considerable measurement repetitiveness of this part in the Machine 1. In addition to that, the boxplot reinforces that there is a measurement problem on the Machine 1, where it is possible to identify the presence of the outlier.

In order to identify an outlier in part 7 for the Machine 1, a new analysis was performed for the US characteristic. Given the parameter configuration $x_{\text {uncoded }}^{*}=[7 ; 74 ; 17 ; 83]$, a new experiment was carried out under the same conditions, aiming to replace the outlier and perform a new diagnosis (TSS $=5219.7 \mathrm{~N} ; U S=1.72 \mathrm{~mm}$ ). The results of the new $N G R \& R$ study, for US characteristics, showed that the $\% R \& R$ was $48.31 \%$, after outlier removal, reducing the variability of the measurement system. However, it is still classified as unacceptable according to AIAG recommended criteria [23]. It is important to highlight that for the TSS there was no statistically significant difference.
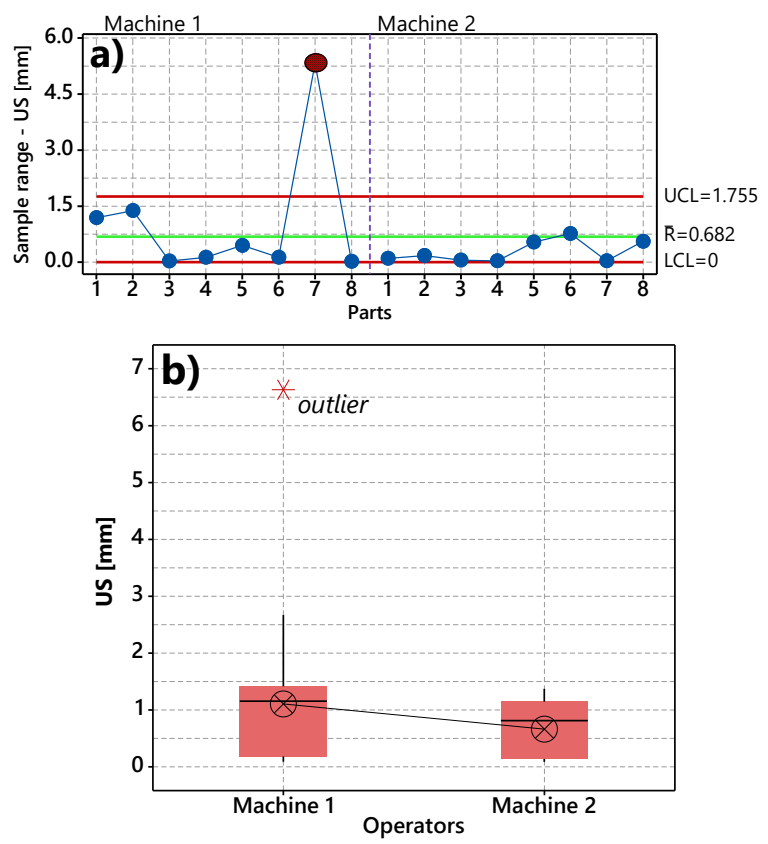

Fig. 8. a) Control R Chart for US characteristic, and b) boxplot for US characteristic

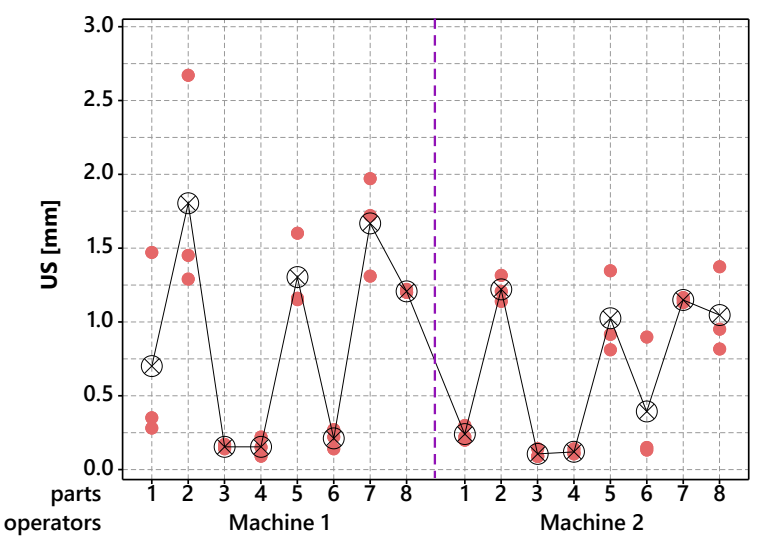

Fig. 9. Measurement dispersions to the US after outlier removal

Fig. 9 highlights the metric dispersions for the US characteristic after the removal of an outlier in part 7 , evidencing the metrics behavior of each part.

Because of outlier removal, the upper limit control (UCL) presented a new range, going from 
a value $\mathrm{UCL}=1.755$ to $\mathrm{UCL}=1.005$. Lower limit control (LCL) remains the same. Thus, the control $\mathrm{R}$ chart now has two out of control points in part 1 and 2 for Machine 1, as seen in Fig. 10.

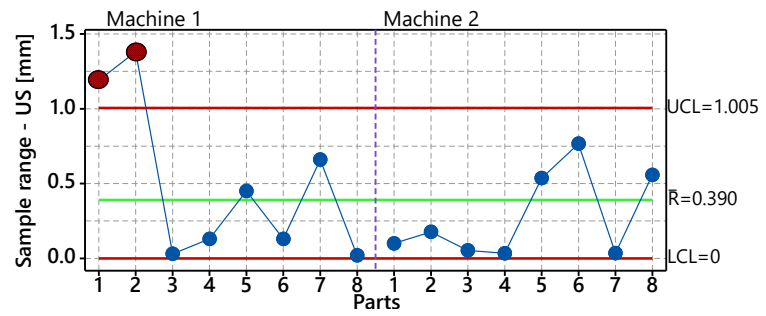

Fig. 10. Control $R$ Chart for US characteristic without outiler

\subsection{Analysis of the Results}

After verifying the results from the gage study by using the ANOVA method, it was found that, although one of the characteristics presents a result of variation classified as acceptable, there is a great variability attributed to the Machine 1 (EMIC ${ }^{\circledR}$ machine), presenting less repeatability for the measurements, as well as an out-of-control point for part 7. After detecting this variation cause, the new study showed that the $\% R \& R$ decreased, but still remained unacceptable for MS. This result can be explained since the Machine 1 did not exhibit an adequate behavior during the tests, as it led to specimens slips, implying in a non-faithful reading of the CTQ even with the proper preparation usually performed for this procedure.

It can be inferred, from this analysis, that Machine 1 needs adjustments and improvements, especially with respect to the parts fitting in the machine, since its coupling presented slips during the test due to the metal part composition, which presents a layer of zinc (galvanized steel). Such an improvement could hold the coupling of the part during the shear test in order to not compromise future diagnostics in tests performed by it. Fig. 11 shows the boxplot, which illustrates the form, central tendency and variability of the sample analyzed for the TSS characteristic (Fig. 11a) and US (Fig. 11b). Fig. 12, in turn, presents the result from the gage run chart for the two characteristics analyzed, in which is possible to verify that the test outcomes from Machine 2 present greater homogeneity than the results obtained by the Machine 1 .

\section{CONCLUSION}

In order to verify the assigned variability of the measuring instrument for the resistance spot welding
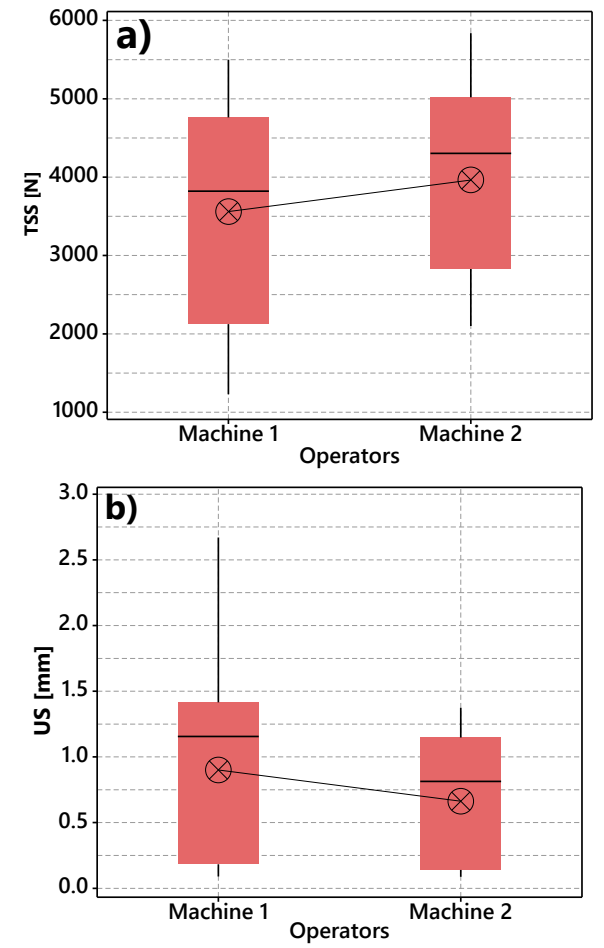

Fig. 11. Boxplot for a) TSS and b) US
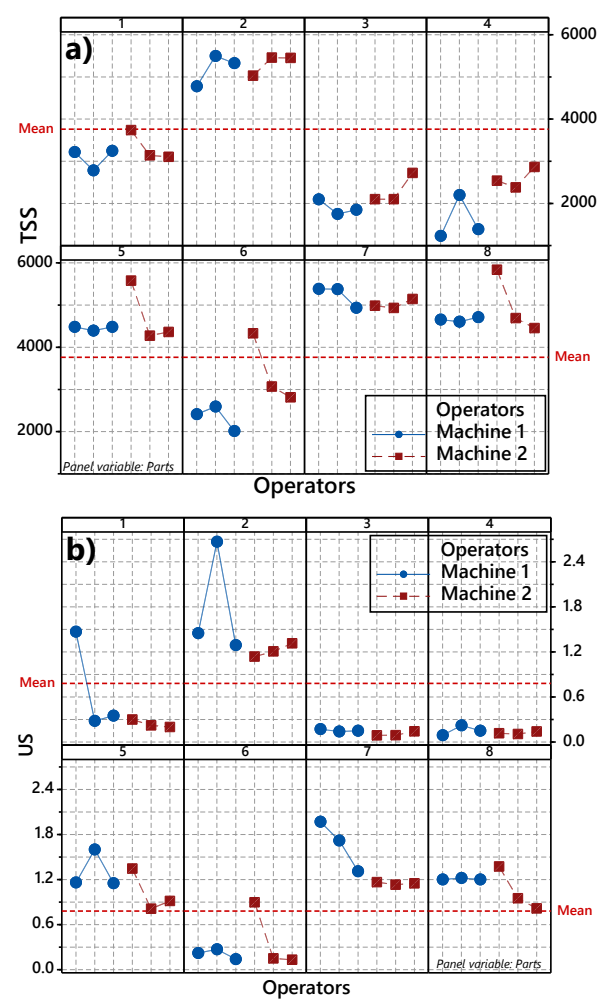

Fig. 12. Gage Run Chart for a) TSS and b) US

process. A MSA for the shear test, by using different tensile machines, was performed in this paper, in 
order to verify the reliability of the outcomes obtained in the RSW process.

From the shear test analysis, it was possible to verify that the Machine 1 was responsible for the greater contribution on the system variability, presenting measurement results outside the control, as well as a lower degree of repetitiveness than Machine 2. In addition to that, Machine 1 was not well adjusted, since some specimens have slipped during the tests. This result evidences that some improvements in the parts coupling, which have a coating (such as galvanized steel) are necessary in order to avoid future slips and, therefore, to favor more reliable results, without compromising future diagnoses in tests performed by this type of equipment.

Regarding the specimens, it was verified that part 7 presented greater variability in measurements, especially for Machine 1, which may indicate a generalized measurement error for this part. In addition, after identifying this outlier, the new study showed a decrease in the variability of the measurement system to the US characteristic, being able to identify new out of control points in parts 1 and 2.

\section{ACKNOWLEDMENTS}

The authors would like to acknowledge the support from CNPq, CAPES and FAPEMIG.

\section{REFERENCES}

[1] Gomes, G.F., Viéville, P., Durrenberger, L. (2017) Dynamic behavior investigation of spot welding machines and its influence on weld current range by modal analysis. Journal of the Brazilian Society of Mechanical Sciences and Engineering, vol. 39, no. 3, p. 765-773, Dol:10.1007/s40430-016-0580-0.

[2] Zhang, Y., Li, Y., Luo, Z., Yuan, T., Bi, J., Wang, Z.M., Wang, Z.P., Chao, Y.J. (2016). Feasibility study of dissimilar joining of aluminum alloy 5052 to pure copper via thermo-compensated resistance spot welding. Materials \& Design, vol. 106, p. 235246, D0I:10.1016/ j.matdes.2016.05.117.

[3] Bi, J., Song, J., Wei, Q., Zhang, Y., Li, Y., Luo, Z. (2016). Characteristics of shunting in resistance spot welding for dissimilar unequal-thickness aluminum alloys under large thickness ratio. Materials \& Design, vol. 101, p. 226-235. DOI:10.1016/j.matdes.2016.04.023.

[4] Li, Y.B., Li, Y.T., Shen, Q., Lin, Z.Q. (2013). Magnetically assisted resistance spot welding of dual-phase steel. Welding Journal, vol. 92, no. 4, p. 124-132.

[5] Feng, Y., Li, Y., Luo, Z., Ling, Z., Wang, Z. (2016). Resistance spot welding of $\mathrm{Mg}$ to electro-galvanized steel with hotdip galvanized steel interlayer. Journal of Materials Processing Technology, vol. 236, p. 114-122, D0l:10.1016/j. jmatprotec.2016.05.015.
[6] Zhang, Y., Luo, Z., Li, Y., Liu, Z., Huang, Z. (2015). Microstructure characterization and tensile properties of $\mathrm{Mg} /$ Al dissimilar joints manufactured by thermo-compensated resistance spot welding with Zn interlayer. Materials \& Design, vol. 75, p. 166-173, D0l:10.1016/j.matdes.2015.03.030.

[7] Martín, Ó., De Tiedra, P., San-Juan, M. (2017). Combined effect of resistance spot welding and precipitation hardening on tensile shear load bearing capacity of A286 superalloy. Materials Science and Engineering: A, vol. 688, p. 309-314, D0l:10.1016/j.msea.2017.02.015.

[8] Shan, H., Zhang, Y., Li, Y., Luo, Z. (2017). Dissimilar joining of AZ31B magnesium alloy and pure copper via thermo-compensated resistance spot welding. Journal of Manufacturing Processes, vol. 30, p. 570-581, D0l:10.1016/j. jmapro.2017.10.022.

[9] Chen, N., Wang, H. P., Carlson, B. E., Sigler, D. R., Wang, M. (2017). Fracture mechanisms of Al/steel resistance spot welds in lap shear test. Journal of Materials Processing Technology, vol. 243, p. 347-354, D0l:10.1016/J.jmatprotec.2016.12.015.

[10] Manladan, S.M., Yusof, F., Ramesh, S., Zhang, Y., Luo, Z., Ling, Z. (2017). Microstructure and mechanical properties of resistance spot welded in welding-brazing mode and resistance element welded magnesium alloy/austenitic stainless steel joints. Journal of Materials Processing Technology, vol. 250, p. 45-54, DOI:10.1016/J.jmatprotec.2017.07.006.

[11] Podržaj, P., Polajnar, I., Diaci, J., Kariž, Z. (2004). Expulsion detection system for resistance spot welding based on a neural network. Measurement Science and Technology, vol. 15, no. 3, p. 592-598, Dol:10.1088/0957-0233/15/3/011.

[12] Podržaj, P., Polajnar, I., Diaci, J., Kariž, Z. (2005). Estimating the strength of resistance spot welds based on sonic emission. Science and Technology of Welding and Joining, vol. 10, no. 4, p. 399-405, DOI:10.1179/174329305X44107.

[13] Podržaj, P., Polajnar, I., Diaci, J., Kariž, Z. (2006). Influence of welding current shape on expulsion and weld strength of resistance spot welds. Science and Technology of Welding and Joining, vol. 11, no. 3, p. 250-254, D0I:10.1179/174329306X101391.

[14] Podržaj, P., Simončič, S. (2013). Resistance spot welding control based on the temperature measurement. Science and Technology of Welding and Joining, vol. 18, no. 7, p. 551-557, DOI:10.1179/1362171813Y.0000000131.

[15] Simončič, S., Podržaj, P. (2012). Image-based electrode tip displacement in resistance spot welding. Measurement Science and Technology, vol. 23, no. 6, p. 1-7, DOI:10.1088/0957-0233/23/6/065401.

[16] Simončič, S., Podržaj, P. (2014). Resistance spot weld strength estimation based on electrode tip displacement/velocity curve obtained by image processing. Science and Technology of Welding and Joining, vol. 19, no. 6, p. 468-475, Dol:10.1179/ 1362171814 Y.0000000212.

[17] Podržaj, P., Polajnar, I., Diaci, J., Kariž, Z. (2008). Overview of resistance spot welding control. Science and Technology of Welding and Joining, vol. 13, no. 3, p. 215-224, DOl:10.1179/174329308X283893.

[18] Majeske, K.D. (2008). Approval criteria for multivariate measurement systems. Journal of Quality Technology, vol. 40, no. 2, p. 140-153, D0I:10.1080/00224065.2008.11917721. 
[19] Pereira, R.B.D., Peruchi, R.S., de Paiva, A.P., da Costa, S.C., Ferreira, J.R. (2016). Combining Scott-Knott and GR\&R methods to identify special causes of variation. Measurement, vol. 82, p. 135-144, Dol:10.1016/j.measurement.2015.12.033.

[20] Woodall, W.H., Borror, C.M. (2008). Some relationships between gage R\&R criteria. Quality and Reliability Engineering International, vol. 24, no. 1, p. 99-106, D0l:10.1002/qre.870.

[21] Senol, S. (2004). Measurement system analysis using designed experiments with minimum $\alpha-\beta$ Risks and $n$. Measurement, vol. 36, no. 2, p. 131-141, D0l:10.1016/j. measurement.2004.05.001.

[22] Peruchi, R.S., Paiva, A.P., Balestrassi, P.P., Ferreira, J.R., Sawhney, R. (2014). Weighted approach for multivariate analysis of variance in measurement system analysis. Precision Engineering, vol. 38, no. 3, p. 651-658, Dol:10.1016/j.precisioneng.2014.03.001.

[23] Automotive Industry Action Group - AIAG (2010). Measurement systems analysis - Reference Manual. $4^{\text {th }}$ ed. Chrysler, Ford, General Motors Supplier Quality Requirements Task Force.

[24] Al-Refaie, A., Bata, N. (2010). Evaluating measurement and process capabilities by GR\&R with four quality measures. Measurement, vol. 43, no. 6, p. 842-851, D0l:10.1016/ j.measurement.2010.02.016.

[25] Awad, M., Erdmann, T.P., Shanshal, Y., Barth, B. (2009). A measurement system analysis approach for hard-to-repeat events. Quality Engineering, vol. 21, no. 3, p. 300-305, DOI:10.1080/08982110902852344.

[26] Burdick, R.K., Borror, C.M., Montgomery, D.C. (2003). A review of methods for measurement systems capability analysis. Journal of Quality Technology, vol. 35, no. 4, p. 342-354, DOl:10.1080/00224065.2003.11980232.

[27] Wu, C.W., Pearn, W.L., Kotz, S. (2009). An overview of theory and practice on process capability indices for quality assurance. International Journal of Production Economics, vol. 117, no. 2, p. 338-359, D0l:10.1016/j.ijpe.2008.11.008.

[28] Erdmann, T.P., Does, R.J., Bisgaard, S. (2009). Quality quandaries*: A gage R\&R study in a hospital. Quality Engineering, vol. 22, no. 1, p. 46-53, DOI:10.1080/08982110903412924.

[29] Knowles, G., Vickers, G., Anthony, J. (2003). Implementing evaluation of the measurement process in an automotive manufacturer: a case study. Quality and Reliability Engineering International, vol. 19, no. 5, p. 397-410, Dol:10.1002/qre.533.

[30] Polini, W., Turchetta, S. (2004). Test protocol for microgeometric wear of sintered diamond tools. Wear, vol. 257, no. 3-4, p. 246-256, D0I:10.1016/j.wear.2003.12.008.

[31] Wang, F.K., Chien, T.W. (2010). Process-oriented basis representation for a multivariate gauge study. Computers \& Industrial Engineering, vol. 58, no. 1, p. 143-150, Dol:10.1016/j.cie.2009.10.001.

[32] Shi, L., Chen, W., Lu, L.F. (2014). An approach for simple linear profile gauge R\&R studies. Discrete Dynamics in Nature and Society, vol. 2014, Dol:10.1155/2014/816980.

[33] Deshpande, A.A., Ramya, A., Vishweshwar, V., Deshpande, G.R., Roy, A.K. (2014). Applications of gage reproducibility \& repeatability (GRR): understanding and quantifying the effect of variations from different sources on a robust process development. Organic Process Research \& Development, vol. 18, no. 12, p. 1614-1621, D0l:10.1021/op5002935.

[34] Zhu, X., Zhao, Z., Wang, L., Zhang, L. (2014). A new method to measure fat content in coconut milk based on Y-type optic fiber system. Optik-International Journal for Light and Electron Optics, vol. 125, no. 20, p. 6172-6178, Dol:10.1016/ j.ijleo.2014.06.115.

[35] García, A.C., del Río, A.G. (2013). Number of distinct data categories and gage repeatability and reproducibility. A double (but single) requirement. Measurement, vol. 46, no. 8, p. 2514-2518, D0I:10.1016/j.measurement.2013.04.065.

[36] Johnson, J.A., Widener, S., Gitlow, H., Popovich, E. (2006). A "Six Sigma" (C) black belt case study: GEP Box's paper helicopter experiment part A. Quality Engineering, vol. 18, no. 4, p. 413-430, Dol:10.1080/08982110600875894.

[37] Wan, X., Wang, Y., Zhao, D., Huang, Y., Yin, Z. (2017). Weld quality monitoring research in small scale resistance spot welding by dynamic resistance and neural network. Measurement, vol. 99, p. 120-127, D0l:10.1016/j. measurement.2016.12.010.

[38] Degidi, M., Caligiana, G., Francia, D., Liverani, A., Olmi, G., Tornabene, F. (2016). Strain gauge analysis of implantsupported, screw-retained metal frameworks: Comparison between different manufacturing technologies. Proceedings of the Institution of Mechanical Engineers, Part H: Journal of Engineering in Medicine, vol. 230, no. 9, p. 840-846, DOI:10.1177/0954411916653623.

[39] Wang, L., Hou, Y., Zhang, H., Zhao, J., Xi, T., Qi, X., Li, Y. (2016). A new measurement method for the dynamic resistance signal during the resistance spot welding process. Measurement Science and Technology, vol. 27, no. 9, p. 1-12, DOI:10.1088/0957-0233/27/9/095009.

[40] Xia, Y.J., Zhang, Z.D., Xia, Z.X., Zhu, S.L., Zhang, R. (2015). A precision analogue integrator system for heavy current measurement in MFDC resistance spot welding. Measurement Science and Technology, vol. 27, no. 2, p. 1-11, DOI:10.1088/0957-0233/27/2/025104.

[41] Al-Jader, M.A., Cullen, J.D., Shaw, A., Al-Shamma'a, A.I. (2011). Theoretical and practical investigation into sustainable metal joining process for the automotive industry. Journal of Physics: Conference Series, vol. 307, no. 1, p. 012044 , DOl:10.1088/1742-6596/307/1/012044.

[42] Lei, Z., Kang, H.-T., Reyes, G. (2010). Full field strain measurement of resistant spot welds using 3D image correlation systems. Experimental Mechanics, vol. 50, no. 1, p. 111-116, DOl:10.1007/s11340-008-9186-5.

[43] Lai, X.M., Luo, A.H., Zhang, Y.S., Chen, G.L. (2009). Optimal design of electrode cooling system for resistance spot welding with the response surface method. The International Journal of Advanced Manufacturing Technology, vol. 41, no. 3-4, p. 226-233, DOl:10.1007/s00170-008-1478-5.

[44] Almeida, F.A., Gomes, G.F., De Paula, V.R., Corrêa, J.E., Paiva, A.P., Gomes, J.H.F., Turrioni, J.B. (2018). A weighted mean square error approach to the robust optimization of the surface roughness in an AISI 12L14 free-machining steelturning process. Strojniški vestnik - Journal of Mechanical Engineering, vol. 64, no. 3, p. 147-156, Dol:10.5545/svjme.2017.4901. 
[45] Zhang, H., Senkara, J. (2011). Resistance Welding: Fundamentals and Applications. CRC press, Boca Raton.

[46] Wan, Z., Wang, H.P., Chen, N., Wang, M., Carlson, B.E. (2017). Characterization of intermetallic compound at the interfaces of Al-steel resistance spot welds. Journal of Materials Processing Technology, vol. 242, p. 12-23, D0l:10.1016/j. jmatprotec.2016.11.017.

[47] Zhang, Y., Shan, H., Li, Y., Guo, J., Luo, Z., Ma, C.Y. (2017). Joining aluminum alloy 5052 sheets via novel hybrid resistance spot clinching process. Materials \& Design, vol. 118, p. 36-43, DOI:10.1016/j.matdes.2017.01.017.

[48] Pouranvari, M. (2017). Fracture toughness of martensitic stainless steel resistance spot welds. Materials Science and Engineering: A, vol. 680, p. 97-107, D0l:10.1016/j. msea.2016.10.088.

[49] Ighodaro, O.L., Biro, E., Zhou, Y.N. (2016). Comparative effects of Al-Si and galvannealed coatings on the properties of resistance spot welded hot stamping steel joints. Journal of Materials Processing Technology, vol. 236, p. 64-72, DOI:10.1016/J.jmatprotec.2016.03.021.

[50] Fan, Q., Xu, G., Gu, X. (2016). Expulsion characterization of stainless steel resistance spot welding based on dynamic resistance signal. Journal of Materials Processing Technology, vol. 236, p. 235-240, D0l:10.1016/J.jmatprotec.2016.05.026.

[51] Moos, S., Vezzetti, E. (2015). Resistance spot welding process simulation for variational analysis on compliant assemblies. Journal of Manufacturing Systems, vol. 37, p. 44-71, D0I:10.1016/J.jmsy.2015.09.006.

[52] Amaral, F.F., Almeida, F.A., Costa, S.C., Leme, R.C., Paiva, A.P. (2018). Application of the Response Surface Methodology for Optimization of the Resistance Spot Welding Process in AISI 1006 Galvanized Steel. Soldagem \& Inspeção. DOI:10.1590/0104-9224/SI2302.02.

[53] Florea, R.S., Bammann, D.J., Yeldell, A., Solanki, K.N., Hammi, Y. (2013). Welding parameters influence on fatigue life and microstructure in resistance spot welding of 6061T6 aluminum alloy. Materials \& Design, vol. 45, p. 456-465, DOI:10.1016/j.matdes.2012.08.053.

[54] Podržaj, P., Simončič, S. (2011). Resistance spot welding control based on fuzzy logic. The International Journal of
Advanced Manufacturing Technology, vol. 52, no. 9-12, p. 959-967, D0I:10.1007/s00170-010-2794-0.

[55] Podržaj, P., Jerman, B., Simončič, S. (2016). Poor fit-up condition in resistance spot welding. Journal of Materials Processing Technology, vol. 230, p. 21-25, D0l:10.1016/j. jmatprotec.2015.11.009.

[56] Zhou, M., Zhang, H., Hu, S. J. (2003). Relationships between quality and attributes of spot welds. Welding Journal, vol. 82, no. 4, p. 72-S-77-S.

[57] Darwish, S.M., Al-Dekhial, S.D. (1999). Micro-hardness of spot welded (B.S. 1050) commercial aluminium as correlated with welding variables and strength attributes. Journal of Materials Processing Technology, vol. 91, no. 1-3, p. 43-51, D0l:10.1016/S0924-0136(98)00414-2.

[58] AWS/SAE (2002). Recommended Practices for Test Methods for Evaluating the Resistance Spot Welding Behavior of Automotive Sheet Steel Materials. American Welding Society, Florida.

[59] Shiau, Y.R. (2001). Decision support for off-line gage evaluation and improving on-line gage usage. Journal of Manufacturing Systems, vol. 19, no. 5, p. 318-331, DOI:10.1016/S0278-6125(01)89004-X.

[60] Montgomery, D.C., Burdick, R.K., Lawson, C.A., Molnau, W.E., Zenzen, F., Jennings, C.L., Shah, H.K., Sebert, D.M., Bowser, M.D., Holcomb, D.R. (2005). A University-based Six Sigma Program. Quality and Reliability Engineering International, vol. 21, no. 3, p. 243-248, D0l:10.1002/qre.631.

[61] White, T.K., Borror, C.M. (2011). Two-dimensional guidelines for measurement system indices. Quality and Reliability Engineering International, vol. 27, no. 4, p. 479-487, D0I:10.1002/qre.1144.

[62] Aquila, G., Peruchi, R.S., Rotela, P.J., Rocha, L. C.S., Queiroz, A.R., Pamplona, E.O., Balestrassi, P.P. (2018). Analysis of the wind average speed in different Brazilian states using the nested GR\&R measurement system. Measurement, vol. 115, p. 217-222, D0I:10.1016/j.measurement.2017.10.048. 